\title{
Perda Auditiva Neurossensorial em Pacientes com Granulomatose de Wegener: Relato de Três Casos e Revisão de Literatura
}

\section{Neurosensory Hearing Loss in Patients with Wegener's Granulomatosis: a Report of Three Cases and Literature Review}

\author{
Ana Paula Monteiro Gomides ${ }^{(1)}$, Eduardo José do Rosário ${ }^{(2)}$, Helenice Martins Borges ${ }^{(3)}$, \\ Marco Aurélio Vignoli( ${ }^{(4)}$, Paulo Madureira de Pádua ${ }^{(5)}$, Renato Castro Alves de Sousa ${ }^{(6)}$
}

\section{RESUMO}

A granulomatose de Wegener é uma vasculite sistêmica que acomete vasos de pequeno e médio calibres. As manifestações clássicas ocorrem no trato respiratório superior, inferior e rins, mas outros órgãos podem ser envolvidos. O sistema auditivo pode ser freqüentemente acometido nas suas várias porções (orelha externa, média e/ou interna) com manifestações diversas. A perda auditiva neurossensorial pode ser conseqüência de alterações na orelha interna e deve ser precocemente reconhecida. $\mathrm{O}$ tratamento rápido e efetivo pode evitar danos irreversíveis. Descrevemos três casos de granulomatose de Wegener e hipoacusia sensorial, com respostas diferentes ao tratamento.

Palavras-chave: granulomatose de Wegener, perda auditiva, disacusia neurossensorial.

\section{INTRODUÇÃO}

A granulomatose de Wegener é uma vasculite granulomatosa necrotizante que afeta predominantemente vasos de pequeno e médio calibres. As manifestações ocorrem, classicamente, no trato respiratório superior, inferior e rins. Outros órgãos como olhos, pele, sistema nervoso, musculoesquelético e trato gastrointestinal também podem ser envolvidos. ${ }^{(1)}$

O acometimento otológico na granulomatose de

\begin{abstract}
Wegener's granulomatosis is a primary systemic vasculitis that affects small and medium-sized vessels. The classical manifestations occur in the upper and lower respiratory tract and in the kidneys, but other organs may be involved. The auditory system can be frequently affect in its various portions (outer, middle and/or inner ear), showing different manifestations. Neurosensory hearing loss might be a consequence of changes in the inner ear and should be recognized early. Rapid and effective treatment may prevent irreversible damage. We report herein three cases of Wegener's granulomatosis and sensory hypoacusis, which responded differently to treatment.
\end{abstract}

Keywords: Wegener's granulomatosis, hearing loss, neurosensory dysacusis.

Wegener já foi bem documentado, embora sua real prevalência permaneça desconhecida. Encontramos uma variação de 15 a $80 \%$ de manifestações auditivas em séries que avaliaram pacientes com Wegener. ${ }^{(2-5)}$

Diversas alterações em vários sítios do sistema auditivo são descritas e podem surgir em qualquer fase de evolução da doença. O reconhecimento precoce destes distúrbios bem como a monitorização e tratamento adequados favorecem o prognóstico destes pacientes. ${ }^{(4)}$

Trabalho realizado na Santa Casa de Belo Horizonte (MG) durante a participação no Projeto Pronuclear da Sociedade Brasileira de Reumatologia (SBR). Recebido em 08/11/05. Aprovado, após revisão, em 19/04/06.

1. Médica Assistente e Preceptora da residência médica do Serviço de Reumatologia da Santa Casa de Belo Horizonte. Membro do Projeto Pronuclear da SBR.

2. Médico Assistente e Coordenador da residência médica do Serviço de Reumatologia da Santa Casa de Belo Horizonte.

3. Fonoaudióloga, especialista em Audiologia, do Serviço de Otorrinolaringologia da Santa Casa de Belo Horizonte.

4. Médico Assistente e Preceptor da residência médica do Serviço de Reumatologia da Santa Casa de Belo Horizonte.

5. Chefe do Serviço de Reumatologia da Santa Casa de Belo Horizonte.

6. Médico Assistente do Serviço de Otorrinolaringologia da Santa Casa de Belo Horizonte.

Endereşo para Correspondência: Ana Paula Monteiro Gomides e Paulo Madureira de Pádua, Av. Francisco Sales, 1.111, Andar 7B, Sala de Reumatologia, Bairro Funcionários, CEP 30150-221, Belo Horizonte, Minas Gerais, Brasil, telefone (38) 3676-6646/(31) 9628-5487, e-mail: anapmgomides@terra.com.br 


\section{RELATO DE CASOS}

\section{CASO 1}

Paciente do sexo masculino, 30 anos, com dois meses de evolução de hipoacusia bilateral, rinorréia, otorréia, prostração intensa, emagrecimento e cefaléia.

Ao exame físico, apresentava-se emagrecido, com paralisia facial periférica bilateral. Na ausculta respiratória, havia diminuição do murmúrio vesicular na base direita. Exames complementares revelaram: hemograma, urina rotina, hemoculturas, função renal e íons normais; anti-HIV: negativo, VHS $103 \mathrm{~mm} / \mathrm{lh}, \mathrm{PCR}<6 \mathrm{mg} / \mathrm{dL}$, c-ANCA positivo 1:80. Raio X e tomografia computadorizada (TC) de tórax evidenciaram imagem de consolidação com cavitações no seu interior em lobo inferior do pulmão direito. TC de seios da face revelou uma pansinusite. Audiometria demonstrou anacusia na orelha direita e hipoacusia mista de grau severo na orelha esquerda. Biópsia de septo e mucosa nasais em locais aparentemente sem lesão (duas amostras): processo inflamatório em atividade com granulomas e sinais de vasculite, com pesquisa negativa para fungos, bacilos álcool-ácido resistentes (BAAR) e parasitos. Foi iniciada antibioticoterapia e, posteriormente, pulsoterapia mista (metilprednisolona e ciclofosfamida) seguida de prednisona $60 \mathrm{mg} /$ dia e ciclofosfamida oral ( $2 \mathrm{mg} / \mathrm{kg} / \mathrm{dia})$. Após 12 meses do início do tratamento, houve melhora importante do quadro com remissão da paralisia facial, da surdez e diminuição acentuada da lesão pulmonar. Atualmente, o paciente se mantém estável, em tratamento de manutenção.

\section{CASO 2}

Paciente do sexo feminino, 42 anos, evoluindo há seis meses com sinusite de repetição, protrusão discreta de globo ocular direito, zumbidos, perda progressiva da audição e alterações sensitivo-motoras de membros inferiores.

Ao exame, apresentava-se corada e hidratada, com protrusão leve de globo ocular direito. Surdez importante com dificuldade de comunicação. Durante a propedêutica, foram evidenciados neuropatia periférica de membros inferiores, glomerulonefrite com glomeruloesclerose focal e espessamento mesangial. Exames laboratoriais revelaram $\mathrm{Hb}$ 10,5 $\mathrm{mg} / \mathrm{dl}$, VHS $30 \mathrm{~mm} / \mathrm{lh}$, FAN e ANCA negativos. Raio X de tórax sem alterações. Audiometria com anacusia bilateral. TC de órbitas revelou espessamento na camada posterior do globo ocular direito. Biópsia de tecido nasal evidenciou processo inflamatório crônico com presença de granulomas. Pesquisa para fungos, leishmaniose e BAAR foi negativa.
Diante do quadro, recebeu o diagnóstico de granulomatose de Wegener. Foi iniciado tratamento com pulsoterapia mista mensal (seis ciclos), seguida de ciclofosfamida oral (2 mg/kg).

Após um ano de tratamento, houve melhora do estado geral, da sinusopatia e doença renal. Entretanto, manteve quadro de surdez irreversível.

\section{CASO 3}

Paciente do sexo feminino, 50 anos, apresentava quadro de dois meses de evolução de sinusite, otite média refratária com perda auditiva, dispnéia aos médios esforços.

Ao exame, se apresentava corada e hidratada. Taquipnéia leve. Ausculta do aparelho respiratório mostrou diminuição do murmúrio vesicular à esquerda. Exames complementares realizados: VHS $50 \mathrm{~mm} / \mathrm{lh}$ e PCR > 12, $\mathrm{Hb}$ : $10 \mathrm{mg} / \mathrm{dl}$ com normocromia e normocitose. Urina rotina sem alterações. C-ANCA positivo 1:320. FAN e pANCA negativos. Raio X e TC de tórax: massa escavada e com nível hidroaéreo em lobo inferior do pulmão esquerdo. Audiometria com hipoacusia mista moderada bilateral.

Após diagnóstico de granulomatose de Wegener foi iniciado o tratamento com prednisona $1 \mathrm{mg} / \mathrm{kg} / \mathrm{dia}$ e ciclofosfamida $2 \mathrm{mg} / \mathrm{kg} /$ dia. Paciente evoluiu com neutropenia febril grave e sepse após dois meses de tratamento. Foi internada em unidade de terapia intensiva evoluindo para o óbito.

\section{DISCUSSÃO}

A granulomatose de Wegener pode acometer a orelha externa, média ou interna causando perda auditiva de condução, neurossensorial ou mista ${ }^{(6)}$. As manifestações na orelha externa, como otite e condrite auricular, não são comuns.

Em 2002, Llompart et al ${ }^{(2)}$ relataram 2 casos de condrite em uma série de 21 pacientes. Em outro estudo com 13 casos, apenas 1 caso de otite externa refratária foi relatado, todavia em associação com otite média. ${ }^{(7)}$

A orelha média é o local mais freqüentemente acometido. A otite média serosa é a principal manifestação e pode estar associada à infecção ou obstrução da nasofaringe ${ }^{(8)}$. A otite média crônica supurativa muitas vezes leva à suspeita da doença pelo seu caráter refratário ou recorrente e pode ser a primeira manifestação na doença limitada ${ }^{(9)}$. A perda auditiva de condução pode ser uma complicação destas alterações.

A perda auditiva neurossensorial pode ocorrer como conseqüência do envolvimento da orelha interna. Takagi et $a^{(4)}$ estudaram retrospectivamente 15 casos de 
granulomatose de Wegener com acometimento auditivo dentre os quais 2 apresentaram perda profunda. Outro estudo constatou perda auditiva leve a moderada em 28 de 36 exames audiométricos de pacientes com Wegener ${ }^{(3)}$. Outros trabalhos evidenciaram alterações sensoriais, embora menos comuns do que as alterações de orelha média. $(2,5,6,10)$

A apresentação da doença imune da orelha interna na granulomatose de Wegener é muito variável. Pode haver hipoacusia uni ou bilateral, geralmente assimétrica, acompanhada ou não de outros sintomas como vertigem, tinnitus e plenitude auricular.

O início dos sintomas pode ser abrupto ou insidioso. Casos de evolução rápida com perdas graves e irreversíveis podem ocorrer e são comparadas à glomerulonefrite rapidamente progressiva. ${ }^{(11)}$

Os mecanismos precisos das alterações da orelha interna ainda são indefinidos, fato dificultado pela impossibilidade de estudo anatomopatológico (tecido profundo de difícil acesso) e limitações para seleção de pacientes não-tratados. Vasculite local, lesão por imunocomplexos, hidropisia endolinfática e degeneração neuronal provavelmente estão envolvidos na etiopatogenia. ${ }^{(12)}$

O diagnóstico das alterações neurossensoriais na granulomatose de Wegener deve ser feito através de avaliação especializada (otorrinolaringológica) e realização de audiometria. TC e ressonância magnética $(\mathrm{RM})$ poderão ser necessárias na dependência do caso para melhor avaliação estrutural e diagnóstico diferencial com outras patologias.

A associação de hipoacusia e níveis séricos de ANCA não foi comprovada ${ }^{(13)} \mathrm{e}$, de forma semelhante ao caso 2 , há descrição na literatura de perda auditiva em portadores

\section{REFERÊNCIAS}

1. Klippel JH, Dieppe PA: Rheumatology, vol. 2, second edition, Mosby International, 1998.

2. Llompart X, Aumaitre O, Kemeny JL, MomT, Gilais L: Early otorhinolarygological manifestations of Wegener's granulomatosis. Ann Otolaryngol Chir Cervicofac 119: 330-6, 2002.

3. Kempf HG, Bootz F, Berg PA: Wegener's granulomatosis: otologic and clinico- immunologic aspects. Laryngorhinootologie 71: 26-30, 1992.

4. Takagi D, NAkamaru Y, Maguchi S, Furuta Y, Fukuda S: Otologic manifestations of Wegener's granulomatosis. Laryngoscope 112: 1684-90, 2002.

5. Kornblut AD, Wolff SM, Fauci AS: Ear disease in patients with Wegener's granulomatosis. Laryngoscope 92 (7 Pt 1): 713-7, 1982.

6. Ohtani I, Baba Y, Suzuki C, Sakuma H, Kano M: Temporal bone pathology in Wegener's granulomatosas. Fukushima J Med Sci 46: 31-9, 2000. de Wegener com ANCA negativo. ${ }^{(14)}$

$\mathrm{O}$ tratamento dos pacientes com alterações auditivas deve ser iniciado precocemente. Este deve ser individualizado, levando-se em conta as manifestações da doença de base e grau de acometimento do aparelho auditivo. A prednisona e ciclofosfamida são as drogas mais usadas, geralmente com boa resposta. Outros imunossupressores como metotrexato, azatioprina e agentes biológicos podem ser opções de medicamentos. ${ }^{(11,12)}$

Descrevemos três casos com hipoacusia neurossensorial em pacientes com granulomatose de Wegener. No caso 1 , a perda auditiva ocorreu concomitantemente às outras manifestações da doença (sinusopatia, lesão pulmonar). O tratamento foi instituído precocemente e de forma agressiva devido à gravidade do quadro. Houve recuperação completa da audição. No caso 2 , apesar do tratamento imunossupressor, a perda auditiva foi irreversível. A demora do acesso à assistência médica e início do tratamento, bem como a evolução rápida da perda sensorial, podem ter contribuído para a evolução insatisfatória do quadro. No caso 3 , houve perda auditiva mista (condução e neurossensorial). Devido à evolução fatal, não foi possível uma avaliação seriada. Portanto, podemos observar respostas diversas ao tratamento nestes casos: boa resposta no caso 1 e seqüelas com grande morbidade no caso 2.

Ressaltamos que todos os pacientes portadores de granulomatose de Wegener, independentemente dos sintomas, deveriam ser submetidos a uma avaliação auditiva completa. O diagnóstico precoce e tratamento imediato favorecem muito o prognóstico dos pacientes com perda auditiva neurossensorial.

7. Illum P, Thorling K: Otological manifestations of Wegener's granulomatosis. Laryngoscope 92 (7 Pt 1): 801-4, 1982.

8. Cossermelli W: Terapêutica em reumatologia, 1a ed, São Paulo, Lemos editorial, 2000.

9. Karmody CS: Wegener's granulomatosis: presentation as an otologic problem. Otolaryngology 86(4 Pt1): 573-84, 1978.

10. Kempf HG: Ear involvement in Wegener's granulomatosis. Clin Otolarynngol Allied Sci 14: 451-6, 1989.

11. Stone JH, Francis HW: Immune- mediated inner ear disease. Curr Opin Rheumatol 12: 32-40, 2000.

12. Rahman MU, Poe DS, Choi HK: Autoimune vestibulo-cochlear disorders. Curr Opin Rheumatol 13: 184-189, 2001.

13. Okamura H, Ohtani I, Anzai T: The hearing loss in Wegener's granulomatosis: relationship between hearing loss and serum ANCA. Auris Nasus Larynx 19: 1-6,1992.

14. Gotkas O, Hiepe F, Paschen C: Wegener's Granulomatosis presented with hearing loss and without positive serologic ANCA. Laryngorhinootologie 83: 180-4, 2004. 